\title{
Root fracture resistance test of cast post using seat and non-seat preparation design in central maxillary incisor
}

\author{
Rikfi Kania Pramanik, Gantini Subrata, Erna Kurnikasari \\ Department of Prosthodontic Faculty of Dentistry Universitas Padjadjaran
}

\section{ABSTRACT}

Post placement is one of the treatment plans supporting the success of a restoration. The design of root canal preparation is a factor in the success of post use. The purpose of this study was to investigate the root fracture resistance of the root canal preparation for cast post with a seat and non-seat preparation. The study was a laboratory experimental study using 20 upper central incisors that met the criteria in the study. Ten incisors were prepared using seat design while the other ten were prepared using nonseat design. Then tested the compressive test by Universal Testing Machine with test speed $0,5 \mathrm{~mm} / \mathrm{min}$. The results of the fracture strength were analyzed using $t$ student statistical test. The analysis showed a significant difference between the non-seat group and the seat group $(\alpha=0.05)$. The average force in the non-seat group was $852.27 \mathrm{~N}$ with a standard deviation of $112.6 \mathrm{~N}$ while the seat group showed a value of $495.78 \mathrm{~N}$ and $82.90 \mathrm{~N}$, respectively. It was concluded therefore that the root fracture resistance in the non-seat root canal preparation design was higher than the seat preparation design.

Key words: Root fracture resistance, post preparation design, cast post, seat

\section{INTRODUCTION}

Choosing a treatment plan is important thing in determining the success of tooth restoration. Cast post is one of the treatment option to determine a successful restoration if the crown structure is badly broken and does not have adequate tooth structure above the gingiva. The design of root canal preparation is one of the factors involve in the successful of post restoration. Cast post space preparation has to be design in order to provide enough retention and strength, while it still preserve the rest of the dentin structure. ${ }^{1}$

In most cases, post space preparation for cast post often removes excessive root dentin. One of the requirements for successful dowel restoration is protecting coronal and radicular tooth structure whenever possible. ${ }^{2}$ Preparation of post space should require minimal removal of additional radicular dentin beyond the requirements for endodontic therapy. Further enlargement of the root canal only weakens the root. Excessive root canal preparation under the orifice will weaken the root and increasing the probabability of root fracture. The key factor that effects successful dowel treatment is the amount of the remaining dentin. The thicker the bulk of the dentin the stronger the foundation for post and core. ${ }^{3-9}$

There are several post space preparation designs that can be made in anterior tooth for cast post-core, such as by making a full core and 
seat, in severely damaged tooth where the crown structure is completely gone (Fig. 1). ${ }^{10}$ Whereas to prevent too much root dentin structure loss, post space preparation without seat can be made (Fig. 1). ${ }^{11,12}$ In many observations, the broken and the bending of the cast post from a soft alloy always occurs in the cervical region.

The effort to prevent or reduce the fracture possibility of the cast post dentin is by making further preparation $1 \mathrm{~mm}$ into the root, so the weakest part of the post, the border between post and core, is more protected from the mastication force. So in this case, the seat is use to increase resistance of post from both bending and detachment. If the cast post is neither bent, displaced, nor broken, there will be no reason for the root to split. ${ }^{7}$

However, in this seat preparation design, more tooth structure is removed from the root, so it probably can weaken the root. The advantages and disadvantages of this seat preparation design have not been scientifically studied yet.

Until recently in the Prosthodontic Department of Oral and Dental Hospital, Faculty of Dentistry Universitas Padjadjaran, the cast post seat preparation design is still use in making anterior post restoration. For that reason, we are interested in studying whether there is any difference in root fracture resistance from preparation using seat or non-seat design in anterior teeth.

The purpose of this study was to find out a better root canal preparation design to enhance the root facture resistance. The result is expected to be used as guidance for dentists in choosing post-space preparation design for a cast post.

\section{MATERIALS AND METHODS}

The method used in this study was experimental method done in laboratory. The study population was 71 central incisors of upper jaw with main criterias: no caries, no restoration, no previous endodontic treatment, no color changes and no cracks on the root surface. Normality test of statistic was done to get a number of teeth with similar size and the result was found 36 teeth with normal distribution by average root length $13 \mathrm{~mm}$ (measured from apex to medio-labial cemento enamel junction/CEJ) and with the average root diameter $5 \mathrm{~mm}$ (measured from the smallest root diameter dimension). From 36 teeth, 20 teeth were taken randomly as study samples. The teeth were divided into 2 groups. The first group would be given non-seat preparation design and the second group seat preparation design. Each group consisted of 10 teeth.

\section{The making of non-seat preparation design}

For the first group, the tooth was cut until $1 \mathrm{~mm}$ above the CEJ and continued with tapered root canal preparation until $10 \mathrm{~mm}$ depth and 1.6 $\mathrm{mm}$ diameter. Whereas for the second group with seat design, preparation of seat was proceed by adding preparation as deep as $1 \mathrm{~mm}$ and $0.7 \mathrm{~mm}$ diameter further into the root canal.

Then wax pattern was made for post and core using inlay wax. The core has to be resembled as vital jacket crown preparation, with $7 \mathrm{~mm}$ cervico-incisal length, $3 \mathrm{~mm}$ mesio-distal width, $1 \mathrm{~mm}$ incisal thickness and lingual wall inclination of $45^{\circ}$ (Fig. 3a). The wax pattern was then casted using orden ( $\mathrm{Cu}-\mathrm{Zn})$ as the cast alloy (Fig. 3b). Cementation of the post core was done by using zinc-phosphate cement.

A jig was made to hold the specimens for compressive strength test. The specimen was embeded in self curing acrylic resin up to $1 \mathrm{~mm}$ below the CEJ in upright position perpendicular to horizontal plane (Fig. 4), in a cylindrical tube with $30 \mathrm{~mm}$ high and $20 \mathrm{~mm}$ diameter. The whole thing was immersed in destilled water during the acrylic polymerization. After it became solid the bottom of the jig was shaped so it could be seated in the assisting device.

The specimens were then placed in the assisting device seat which has $135^{\circ}$ inclination towards the force direction (Fig. 5). This position was arranged to simulate the condition the condition in the mouth. Then the device was activated with $0.5 \mathrm{~mm} / \mathrm{min}$ test speed, with continuous force application until the device stopped by it self when there was fracture in the root. The results of the compressive strength test values were recorded automatically on computer screen in Newton ( $\mathrm{N}$ ). The compressive strength values will be used to determine the root fracture resistance.

All compressive strength datas were analyzed using statistic $t$ student for independent 
data. The data's of the compressive strength were categorized based on the preparation design that was used.

\section{RESULTS AND DISCUSSION}

Based on the compressive strength test result on 20 central incisors of upper jaw, which were divided into non-seat and seat root canal
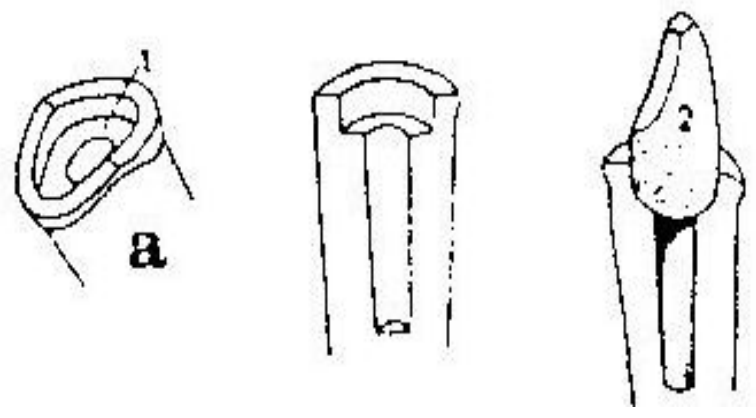

Figure 1. Fullcore and seat. ${ }^{10}$

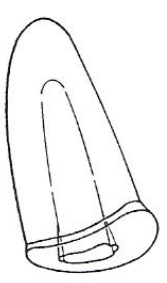

A

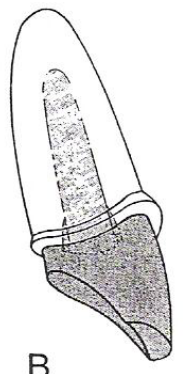

B

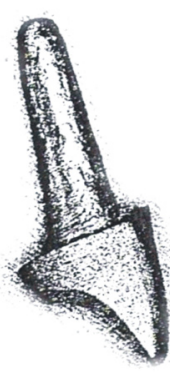

Figure 2. Axis crown without seat. ${ }^{11,12}$
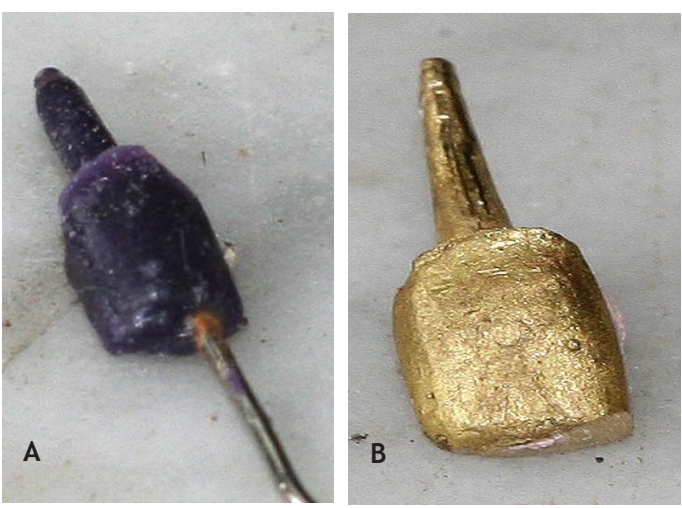

Figure 3. The making of wax pattern and core axis casting. preparation design were compared. From Table 1 it was found that average compressive strength of root canal post preparation with non-seat and seat design were as followed: $852.27 \mathrm{~N}$ and $495.78 \mathrm{~N}$. From Table 2 it was found that the average compressive strength of the root canal preparation with non-seat and seat design showed a statistically significant difference $(P>.05)$. It is proven that the fracture resistance of insicors

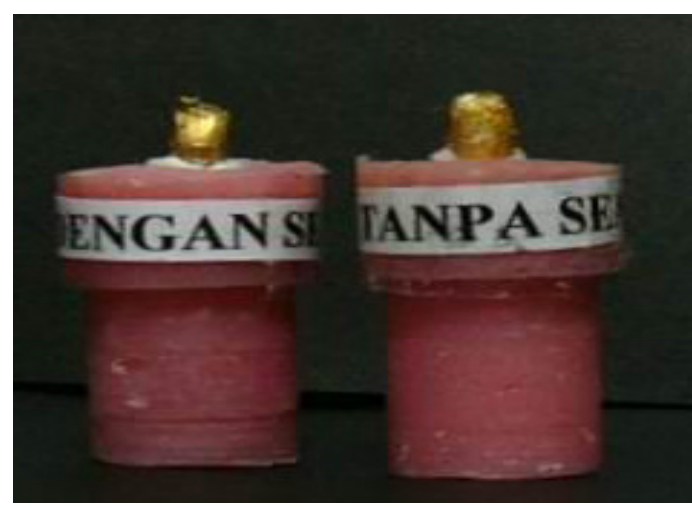

Figure 4. The making of sample and its holder.

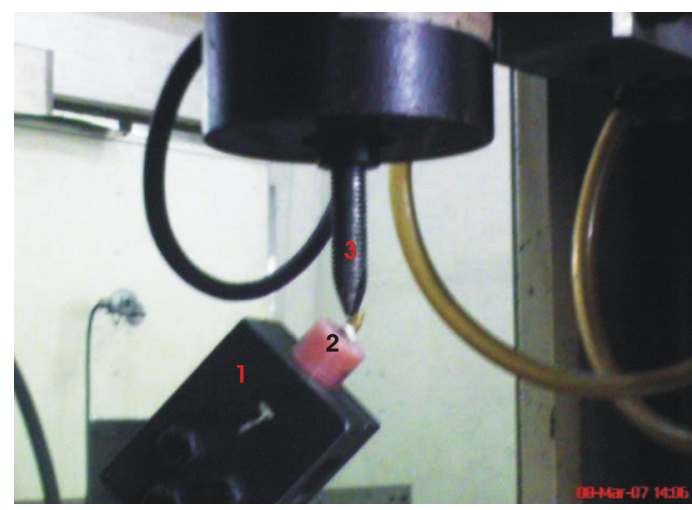

Figure 5. Pressure magnitude testing, sample is placed on the assisting devices placed on the assisting device.

Table 1. Average pressure force on teeth of root canal preparation with seat and without seat.

\begin{tabular}{lcc}
\hline $\begin{array}{c}\text { Incisive } \\
\text { comparison }\end{array}$ & $\begin{array}{c}\text { Average force } \\
\text { magnitude }(\mathbf{N})\end{array}$ & $\begin{array}{c}\text { Deviation } \\
\text { standard }\end{array}$ \\
\hline With seat & 495.78 & 82.90 \\
Without seat & 852.27 & 112.60 \\
\hline
\end{tabular}

Table 2. Test result $\mathrm{t}$ data paired incisives using root canal preparation with seat and without seat.

\begin{tabular}{cccccc}
\hline $\begin{array}{c}\text { Incisive } \\
\text { comparison }\end{array}$ & $\begin{array}{c}\text { Number } \\
\text { of sample }\end{array}$ & $\begin{array}{c}\text { Average force } \\
\text { magnitude }\end{array}$ & $\mathrm{T}_{\text {Count }}$ & $\mathrm{T}_{\text {Table }}$ & Criteria \\
\hline With seat & 10 & 495.78 & 8.062 & 1.83 & Ho denied \\
Without seat & 10 & 852.27 & & & \\
\hline
\end{tabular}


with non-seat design is higher than the seat design group.

This result indicates that the remaining root dentin structure affects the fracture resistance of the root. The more the remaining root structure, the more the fracture resistance of cast post-core restoration. This result supports another studies which indicate that the lost of the tooth structure will affect the tooth strength and increase the risk of the fracture. ${ }^{4-8}$

From the result, it is clear that the operators should maintain root dentin structure as much as possible to strengthen the root resistance against fracture. As other in vitro studies, the clinical application of this study must be considered carefully, according to clinical condition. There are many clinical parameters in this study that are not considered, i.e. periodontal tissue, supporting bones, tooth structure, and also differences in mastication system. All of those clinical parameters above are not simulated in this study. Long term clinical studies are necessary to find out the effect of root canal preparation design on root fracture resistance.

\section{CONCLUSION}

According to this study, it can be concluded that the preservation of the root structure will enhance the fracture resistance of the root restored with cast post from orden alloy. The non-seat design group showed the higher fracture resistance compare to seat design group. Nevertheless, further studies to other preparation designs in using post-core restoration have to be conducted, so the consideration in choosing the design will be better. In vitro studies are also needed to be conducted by considering mouth condition for example periodontal tissue, bone structures, and mastication force so the result of the study will be closer to in vivo condition.

\section{REFERENCES}

1. Cohen S, Hargreaves KM. Pathways of the pulp. $9^{\text {th }}$ ed. St. Louis: Mosby; 2006. p. 787-818.

2. Philip LB, Aquilno SA, Graton DG, Standford $C M$, Tan SC, Johnson WT, et al. In vitro fracture resistance of endodontically treated central incisors with varying ferrule heights and configurations. J Prosthet Dent 2005;93:331-6.

3. Pereira JR, de Ornelas F, Conti PC, de Valle AL. Effect of a crown ferrule on the fracture resistance of endodontically treated teeth restored with prefabricated posts. J Prosthet Dent 1995;95:50-4.

4. Walton RE, Torabinejad M. Prinsip dan praktik ilmu endodonsi. $2^{\text {th }}$ ed. Jakarta: EGC; 1997. p. 236-60,339-57.

5. O'Sullivan M. Fixed prosthodontics in dental practice. London: Quintessence Publishing Co., Inc.; 2005. p. 139-52.

6. Martinez-Insua A, da Silva L, Rilo B, Santana $U$. Comparison of the fracture resistance of pulpless teeth restored with a cast post and core or carbon-fiber post with a composite core. J Prosthet Dent 1998;80:527-32.

7. Zhi-Yue L, Yu Xing Z. Effects of post core design and ferrule on fracture resistance of endodontically treated maxillary central incisors. J Prosthet Dent 2003;89:368-73.

8. Ferrari M, Scotti R. Fiber post characteristics and clinical applications. Italy: Masson; 2002. p. 1-11,93,131-2.

9. Schwartz RS, Robbins JW. Post placement and restoration of endodontically treated teeth. A literature review. J Endodont 2004;30:289-5.

10. Martanto P. Teori dan praktek ilmu mahkota dan jembatan. Bandung: Alumni; 1985. p. 40-58.

11. Shillingburg HT. Fundamentals of fixed prosthodontics. $3^{\text {rd }}$ ed. Chicago: Quintessence Publishing Co., Inc.; 1997. p. 196

12. Smith BGN. Planning and making crown and bridges. London: Martin Dunitz; 1990. p. 105-10. 